TERRITORIO

PROYECTO

PATRIMONIO
2ЭОАОITИヨ

2TATITИ

2 ЭІІІІТИ

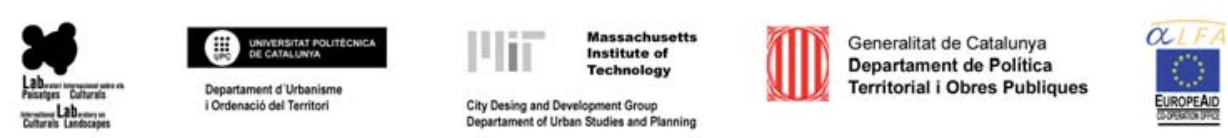

$\sim$

ए

$\varangle$

$\frac{\square}{\square}$

$z$

ш

$\stackrel{-}{-}$

s.

PATRINONIO

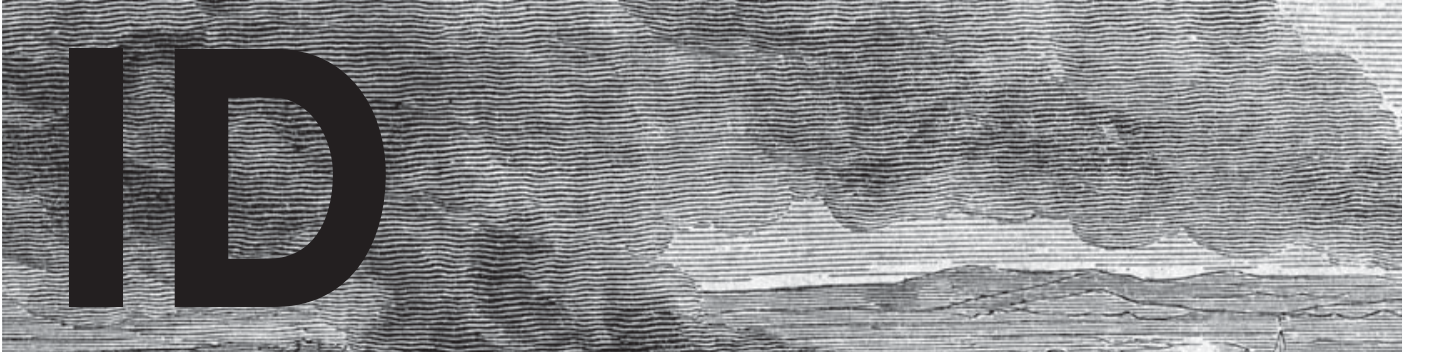

LABORATORIO INTERNACIONAL DE PAISAJES CULTURALES

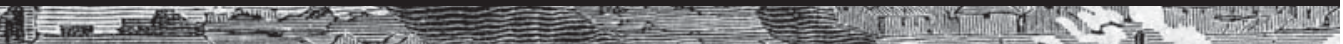

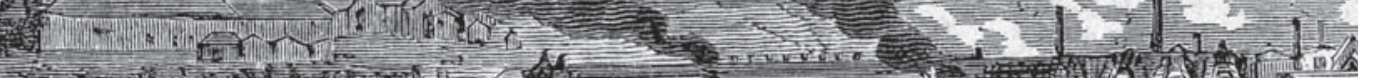

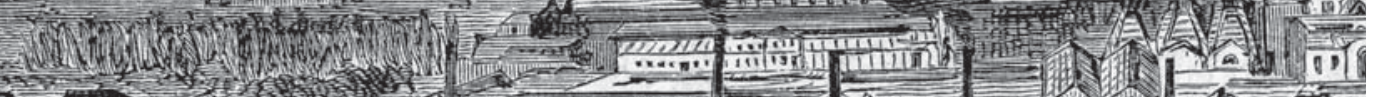

h.

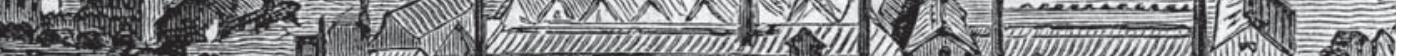

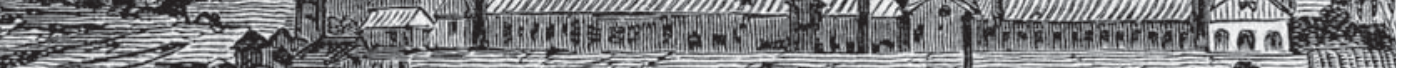

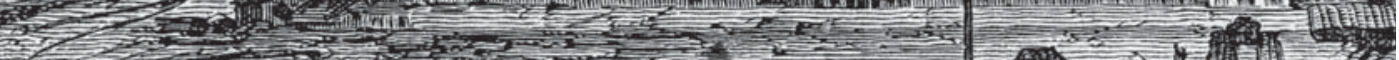

EDITORIAL Laboratorio Internacional de Paisajes Culturales

ENSAYOS Paz Benito y Joaquín Sabaté - Françoise Fortunet

TRABAJOS José Montasell

INVESTIGACIONES Mariana Debat - Fernando Diaz - Biel Horrach - Pablo Elinbaum

RESEÑAS David Haskell

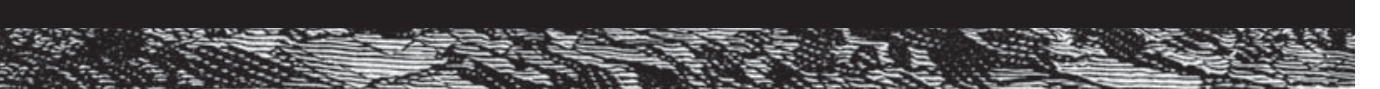




\title{
DATOS CATALOGRÁFICOS
}

\author{
ID entidades \\ ID entitats \\ ID entities
}

Territorio, Proyecto, Patrimonio

\section{EQUIPO REDACTOR}

Román Caracciolo

Mariana Debat

Pablo Elinbaum

Biel Horrach

Joaquín Sabaté (director)

\section{CONSEJO CIENTÍFICO / REFEREES}

André Argollo (Universidad esdual de Campinas)

Dennis Frenchman (Massachusetts Institute of Technology)

Noemí Goytia (Universidad Nacional de Córdoba)

Miquel Martí (Universidad Politécnica de Cataluña)

Isabel Martinez de San Vicente (Universidad Nacional de Rosario)

Joan Nogué (Universidad de Gerona)

Alicia Novick (Universidad de Buenos Aires)

Teresita Núñez (Universidad de Buenos Aires)

Olga Paterlini (Universidad Nacional de Tucumán)

Joaquín Sabaté (Universidad Politécnica de Cataluña)

Pere Vall (Universidad Internacional de Cataluña)

ISBN: 2014 - 0614

Primera edición: diciembre 2010

Tirada: 500 ejemplares

Impresión: Barcelona BD digital 


\section{ÍNDICE}

EDITORIAL

\section{ENSAYOS}

Paisajes culturales y proyecto territorial: un balance de treinta años de experiencias. Paz Benito y Joaquín Sabaté

\section{TRABAJOS}

El parque Agrario del Baix Llobregat. Un paisaje cultural. José Montasell

\section{INVESTIGACIONES}

Impresión y adaptación. La construcción de la identidad del área central de la ciudad de Córdoba. Mariana Debat

Trazas, mojones y poblados del Norte de Traslasierra. Elementos para la definición de una estructura territorial. Fernando Díaz

Mallas turísticas. La reinvención de un tejido como soporte de la actividad vacacional en Mallorca. Biel Horrach

Poble Nou (re)inventado. Paisajes creativos, regeneración urbana y Barcelona 22@. Manuel Tironi

\section{RESEÑAS}

Festival de la ciudad. Joaquín Sabaté, Dennis Frenchman y Mark Schuster introducen el lugar del evento. David Haskell 


\section{EDITORIAL}

Joaquín Sabaté

Ha transcurrido mucho tiempo desde la aparición del anterior número de Identidades. Pero no ha sido en vano, puesto que ha permitido consolidar un grupo de jóvenes investigadores alrededor del proyecto, algunos de cuyos trabajos se recogen aquí. Pero además nos ha permitido recientemente, tras un apasionante Seminario en Campinas, refundar el Laboratorio Internacional de Paisajes Culturales, con la participación de una quincena de centros de investigación de diez países diferentes de Europa y América. Identidades se plantea pues, como otras revistas de esta red, para recoger los estudios, proyectos y realizaciones vinculados a la puesta en valor de los recursos patrimoniales. Pero no se trata tan solo de reivindicar el valor de dicho legado, de reclamar su preservación, sino de utilizar dichos recursos culturales al servicio del desarrollo local, de la mejora de la educación y de la calidad de vida de los habitantes. El objetivo último de los estudios y proyectos, más allá de mantener recursos patrimoniales tangibles e intangibles de un territorio, es fundamentalmente las personas que lo habitan.

Conviene remarcar algunas otras conclusiones de dicho encuentro de Campinas. En todo paisaje cultural, en todo territorio cargado de recursos, y por ello, muy delicado, un requisito absolutamente imprescindible es la existencia de un proyecto, de un modelo ilusionante y compartido hacia el que tender. Y precisamente la novedad de las intervenciones en paisajes culturales obliga a esfuerzos pedagógicos y de renovación disciplinar. Las lecciones derivadas del análisis comparado de casos, la clara ordenación física de los proyectos, la estructura narrativa o la figura de un master plan, constituyen exploraciones y herramientas de enorme interés.

Seguimos necesitando de un gran trabajo colectivo para construir las bases de estudios y proyectos en un campo tan apasionante como novedoso. La rica complejidad de los paisajes culturales exige un nuevo marco conceptual, nuevos métodos e instrumentos. Reclama, en definitiva, de todo nuestro esfuerzo creativo. La preservación de la mayor parte de nuestros recursos patrimoniales solo puede afrontarse a través de la transformación, superando posiciones meramente conservacionistas. Conservar como seña de identidad es algo más que una labor académica, tiene una vertiente económica y social clave. En esta línea los paisajes culturales están llamados a jugar un papel relevante, porque constituyen la expresión de la memoria, de la identidad de un territorio, que se puede ir enriqueciendo sucesivamente. 